TITLE:

\title{
Hull cell tests for evaluating the effects of polyethylene amines as brighteners in the electrodeposition of aluminum from dimethylsulfone-AlCl3 baths
}

\section{$\operatorname{AUTHOR}(S)$ :}

Miyake, Masao; Kubo, Yuki; Hirato, Tetsuji

\section{CITATION:}

Miyake, Masao ... [et al]. Hull cell tests for evaluating the effects of polyethylene amines as brighteners in the electrodeposition of aluminum from dimethylsulfone- $\mathrm{AlCl} 3$ baths.

Electrochimica Acta 2014, 120: 423-428

\section{ISSUE DATE:}

2014-02

URL:

http://hdl.handle.net/2433/182041

\section{RIGHT:}

(C) 2013 Elsevier Ltd.; This is not the published version. Please cite only the published version.; この論文は出版社版でありません。引用の際に は出版社版をご確認ご利用ください。 
Hull cell tests for evaluating the effects of polyethylene amines as brighteners in the electrodeposition of aluminum from dimethylsulfone- $\mathrm{AlCl}_{3}$ baths

Masao Miyake, Yuki Kubo, and Tetsuji Hirato*

Graduate School of Energy Science, Kyoto University

Yoshida-honmachi, Sakyo-ku, Kyoto 606-8501, Japan

\begin{abstract}
Hull cell tests were carried out to examine a series of polyethylene amines to evaluate their abilities as brighteners in the electrodeposition of aluminum from a dimethylsulfone $\left(\mathrm{DMSO}_{2}\right)-\mathrm{AlCl}_{3}$ bath. The tests demonstrated the current density ranges that yielded bright, semi-bright, dull, burnt, and streaked $\mathrm{Al}$ deposits from the baths containing each polyethylene amine at a variety of concentrations. Among the amines examined in this study, triethylenetetramine (TETA) was found to be the most effective brightener, providing a bright $\mathrm{Al}$ deposit with the highest specular reflectance over a wide range of current densities. No correlation was found between the preferential crystal orientation of the $\mathrm{Al}$ and the brightness of the deposit, which along with the acquired scanning electron microscopy images, indicated that surface morphology was primarily responsible for the differences in brightness.
\end{abstract}

Keywords: Hull cell, Electroplating, Brightener, Organic Solvents

\footnotetext{
*hirato.tetsuji.2n@kyoto-u.ac.jp
} 


\section{Introduction}

Aluminum coatings are employed in a wide range of industrial applications from construction materials to optoelectronic components, taking advantage of their excellent properties, including low density, high corrosion resistance, high conductivity, and high light-reflectivity. While most $\mathrm{Al}$ coatings are fabricated by hot-dipping or physical vapor deposition, electrodeposition of $\mathrm{Al}$ is attracting growing attention since complex-shaped objects can be coated evenly, the deposition rate is relatively high, and the thickness of the coatings can be easily controlled. Unlike many other conventional metallic coatings, those consisting of $\mathrm{Al}$ metal cannot be obtained by electrodeposition from aqueous solutions. However, it has been shown to be possible using certain non-aqueous media such as molten salts [1, 2], organic solvents [3], and ionic liquids [4-12]. Among these, dimethlysulfone $\left(\mathrm{DMSO}_{2}\right)$, a molecular organic solvent, has the advantages of being much cheaper than ionic liquids, and more stable and thus easier to handle than the other organic baths such as ethers and aromatic hydrocarbons [3]. In $\mathrm{DMSO}_{2}-\mathrm{AlCl}_{3}$ electrolytes, there are two main soluble $\mathrm{Al}$ species, namely $\mathrm{AlCl}_{4}{ }^{-}$and $\mathrm{Al}\left(\mathrm{DMSO}_{2}\right)_{3}{ }^{3+}$, formed according to the following reaction [13]:

$$
4 \mathrm{AlCl}_{3}+3 \mathrm{DMSO}_{2} \rightarrow \mathrm{Al}\left(\mathrm{DMSO}_{2}\right)_{3}{ }^{3+}+3 \mathrm{AlCl}_{4}^{-}
$$

The electrodeposition of $\mathrm{Al}$ can occur from the solvated cation, $\mathrm{Al}\left(\mathrm{DMSO}_{2}\right)_{3}{ }^{3+}$, whereas the reduction of $\mathrm{AlCl}_{4}{ }^{-}$is not observed within the electrochemical window of the electrolytes. It has been demonstrated that dense, uniform Al coatings with a high corrosion resistance can be electrodeposited from $\mathrm{DMSO}_{2}-\mathrm{AlCl}_{3}$ baths at $\sim 110{ }^{\circ} \mathrm{C}$ [14-22].

However, $\mathrm{Al}$ coatings electrodeposited from $\mathrm{DMSO}_{2}-\mathrm{AlCl}_{3}$ baths are lusterless in most cases, losing their practical value for many applications. As Al has high light 
reflectivity, realization of bright, lustrous Al coatings would expand their potential applications to, for example, decorative coatings and light reflection layers in optical devices such as LEDs. In general, the electrodeposition of bright coatings is achieved by including certain additives, called brighteners, in the electroplating bath [23]. However, effective brighteners for use in the electrodeposition of $\mathrm{Al}$ from $\mathrm{DMSO}_{2}-\mathrm{AlCl}_{3}$ baths have not been well developed to date, with only $\mathrm{ZrCl}_{4}$ [19] and tetraethylenepentamine [22] having been reported to work to any extent. It is known that bright $\mathrm{Al}$ coatings can be electrodeposited from ionic liquid baths with the addition of 1,10-phenanthroline [7], benzene [11], or toluene [8, 9]. However, our preliminary experiments showed that these additives did not work as brighteners in $\mathrm{DMSO}_{2}-\mathrm{AlCl}_{3}$ baths. The presence of a very small amount of 1,10-phenanthroline strongly hindered the electrodeposition of Al, resulting in uneven deposits, while toluene did not affect the appearance of the Al coatings at all.

Previously, we found that tetraethylenepentamine $\left(\mathrm{NH}_{2}\left(\mathrm{CH}_{2} \mathrm{CH}_{2} \mathrm{NH}\right)_{n} \mathrm{H}, n=4\right.$, TEPA) worked as a brightener for the electrodeposition of $\mathrm{Al}$ in a $\mathrm{DMSO}_{2}-\mathrm{AlCl}_{3}$ bath [22]. This motivated us to investigate other polyethylene amines. In the present study, we report on the use of a range of such compounds, from ethylenediamine ( $n=1, \mathrm{EDA})$ to pentaethylenehexamine ( $n=5$, PEHA), with the aim of identifying a better brightener for the formation of brighter $\mathrm{Al}$ deposits at a wide range of current densities. Hull cell tests were used to estimate the current density range in which bright $\mathrm{Al}$ deposits could be obtained in the bath containing each amine. The Hull cell is a trapezoidal box of non-conducting material with one side at a $38^{\circ}$ angle (Fig. 1). An anode is laid against the right angle side and a cathode panel is laid against the sloping side. When a current is passed through the solution contained in the cell, the current density along the sloping 
cathode varies in a known manner. In this way, the character of deposits over a wide range of current densities can be determined in a single experiment, and therefore, the Hull cell test is widely used for the control, evaluation, and development of various kinds of electrodeposition processes $[24,25]$. To date, no detailed Hull test results for Al electrodeposition from non-aqueous solutions have been published, although there was a brief mention in a paper by Abbott et al., where Hull cell tests were performed to optimize the conditions of the electrodeposition of $\mathrm{Al}$ from ionic liquids [10]. The deposition patterns shown in this paper will provide useful information for the comparison and assessment of baths for improved $\mathrm{Al}$ electroplating.

\section{Experimental}

Preparation of the electrolytic bath and the Hull cell tests were carried out in an Ar filled glove box equipped with a circulation system. $\mathrm{DMSO}_{2}(99 \%$, Tokyo Chemical Industry, Japan) and anhydrous $\mathrm{AlCl}_{3}$ grains (Fluka, crystallized, 99\%) were used as the solvent and $\mathrm{Al}$ source, respectively. $\mathrm{EDA}(n=1,>98 \%$, Wako Pure Chemical Industries, Ltd., Japan), diethylenetriamine (DETA, $n=2,>98 \%$, Tokyo Chemical Industry, Japan), triethylenetetramine (TETA, $n=3$, technical grade, Sigma-Aldrich), tetraethylenepentamine (TEPA, $n=4,>95 \%$, Tokyo Chemical Industry, Japan), and PEHA ( $n=5$, technical grade, Sigma-Aldrich) were used as additives. The $\mathrm{DMSO}_{2}$ was used after drying for $24 \mathrm{~h}$ at $60{ }^{\circ} \mathrm{C}$. The water content of the $\mathrm{DMSO}_{2}$ after the drying process was measured to be $<10 \mathrm{ppm}$ by a coulometric Karl-Fischer method (MKC-510 $\mathrm{N}$; Kyoto Electronics Manufacturing Co., Ltd). $\mathrm{AlCl}_{3}$ was used as received. The polyethylene amines were used after drying with molecular sieves (3A) for more than $12 \mathrm{~h}$ at room temperature. The molar ratio of $\mathrm{DMSO}_{2}$ to $\mathrm{AlCl}_{3}$ in the electrolyte was 
10:2. The content of the additives in the electrolyte was adjusted in the range of $0-0.4$ mol with respect to $10 \mathrm{~mol}$ of $\mathrm{DMSO}_{2}$.

The Hull cell tests were conducted using a standard $267 \mathrm{~mL}$ Hull cell made of glass (Yamamoto-MS Co., Ltd). A Cu plate and an Al plate were used as the cathode and anode panels, respectively. Prior to the electrodeposition, the $\mathrm{Cu}$ plate was polished with $\mathrm{SiC}$ paper and then cleaned by sonication in ethanol. The bath was heated to $110^{\circ} \mathrm{C}$ prior to the electrolysis by a ribbon heater wound round the sides of the cell. However, as the conductivity of the $\mathrm{DMSO}_{2}-\mathrm{AlCl}_{3}$ bath is relatively low $\left(\sim 14 \mathrm{mS} \mathrm{cm}{ }^{-1}\right.$ at $\left.110^{\circ} \mathrm{C}\right)$, and the current-to-volume ratio in the Hull cell is high, the bath temperature increases by more than $20^{\circ} \mathrm{C}$ in the first $10 \mathrm{~min}$ after the start of the electrolysis through Joule heating. In order to suppress the temperature increase, the Hull cell was placed on a $30^{\circ} \mathrm{C}$ cool plate (Scinics, CP-1200), where a Peltier device prevented the temperature from rising more than $10^{\circ} \mathrm{C}$. The bath was stirred by a reciprocating agitator (Kocour, Model A83) throughout the electrolysis procedure. The current for the electrolysis was supplied by a direct-current power source (Takasago, EX-750L2).

The Al deposits obtained by the Hull cell tests were characterized at a position of $3 \mathrm{~cm}$ from the bottom edge of the cathode panel at various horizontal distances. Normal incidence specular reflectance values were measured using a multichannel photodetector (MCPD-7700, Otsuka electronics) coupled with an optical microscope (Eclipse LV100, Nikon). The reflectance was captured from a $20 \mu \mathrm{m}$ diameter spot using a $10 \times$ objective lens with a numerical aperture of 0.3 , with reference to an $\mathrm{Al}$ mirror with a $50 \mathrm{~nm} \mathrm{MgF}_{2}$ coating (TFA-25C05-20, Sigma Koki Co., Ltd.). The acquired data were converted to absolute reflectance with the use of the simulated reflectance spectrum for the mirror. A scanning electron microscope (SEM, 
JSM-6510LV, JEOL) was used to observe the cross-sections and surface morphologies of the $\mathrm{Al}$ deposits. X-ray diffraction (XRD) patterns were obtained by employing a diffractometer (X'Pert PRO-MPD, Panalytical) with $\mathrm{Cu}-\mathrm{K} \alpha$ radiation.

\section{Results and Discussion}

The Hull cell tests were conducted at a total current of 2 A for 600 s. Fig. 2 presents photographs of the cathode panels after the Hull cell tests for the baths containing no additives, TETA, and PEHA, showing typical appearances of the resulting $\mathrm{Al}$ deposits. It can be seen in most cases that an $\mathrm{Al}$ deposit with a relatively smooth surface was obtained in the middle area of the cathode panel, while a burnt section and one with streaks were observed near the left edge (high current density end) and right edge (low current density end) of the panel, respectively. The ranges where such deposits appeared depended on the type and quantity of the additive. The formation of the streaked deposit could be attributed to the following hypothesis: during the electrodeposition, a trace amount of a gas could be evolved at the cathode as a by-reaction, with these bubbles blocking the electrodeposition of $\mathrm{Al}$ as they move along the surface of the cathode, resulting in grooves or streaks in the deposit. Impurities such as water could be responsible for this gas evolution. It was sometimes observed that a part of the $\mathrm{Al}$ deposit near the left edge of the panel cracked and dislodged from the substrate (Figs. 2b and 2c). Such cracks only occurred in the area near the left edge of the panel, where the local current density and thus the thickness of the Al deposit were at their highest.

The brightness of the smooth $\mathrm{Al}$ deposit formed in the middle area of the cathode also depended on the additive. The deposit from the bath without additives appeared 
dull-white (Fig. 2a), with that from the bath with TETA looking brighter (Fig. 2b). Variation from dull-white to semi-bright was observed across the length of the deposit from the bath with PEHA (Fig. 2c). In order to quantitatively evaluate the brightness of the deposits, normal incidence reflectance at a wavelength of $550 \mathrm{~nm}$ was measured at various positions on the cathode panels. Fig. 3 presents the quantitative data that correspond to the deposits shown in Fig. 2. The dull-white deposit from the bath with no additive exhibited reflectances of about $20 \%$, while the bright deposit from the bath with TETA gave values above $60 \%$. The reflectance of the deposit from the bath with PEHA varied from 20 to $50 \%$, depending on the position on the cathode. Comparison between the reflectance values and the appearance of the deposits indicated that the areas showing reflectances of $<30 \%, 30-50 \%$, and $>50 \%$, looked dull-white, semi-bright, and bright, respectively.

The current distribution across the surface of the cathode panel was evaluated in order to achieve an estimation of the current density at each area of deposit mentioned above. The current distribution for a $267 \mathrm{~mL}$ Hull cell is commonly approximated using the following formula [25]:

$$
i(x)=I(51.0-52.4 \log x)
$$

where $x$ indicates the distance $(\mathrm{cm})$ along the cathode from the high current edge, $i(x)$ is the local current density $\left(\mathrm{mA} \mathrm{cm}^{-2}\right)$ at distance $x$, and $I$ is the total electrolytic current (A). However, since this formula does not take into account the influence of electrochemical kinetics [26], there was a possibility that the current distribution in the present system would not follow this accurately. Hence, we estimated the local current density from the thickness of the Al deposit obtained on the cathode panel. Fig. 4 shows cross-sectional SEM images of the Al deposit obtained by electrolysis at a total current 
of $2 \mathrm{~A}$ for $600 \mathrm{~s}$ in the $\mathrm{DMSO}_{2}$ bath with no additive. The thickness of the $\mathrm{Al}$ deposit at each position could be determined from the image. The local current densities were calculated using the measured thicknesses, assuming that the density of the Al deposit was $2.70 \mathrm{~g} \mathrm{~cm}^{-3}$ and the current efficiency for the electrodeposition of $\mathrm{Al}$ was $100 \%$ for all the current densities. The approximation of $100 \%$ efficiency was based on a previous report that stated that the current efficiency for $\mathrm{Al}$ electrodeposition in a $\mathrm{DMSO}_{2}$ bath was in the range of $97-99.5 \%$ at current densities of $50-150 \mathrm{~mA} \mathrm{~cm}^{-2}$ at $130^{\circ} \mathrm{C}$ [20]. For further confirmation, we determined that the current efficiency was $97 \%$ at $40 \mathrm{~mA} \mathrm{~cm}^{-2}$ at $110^{\circ} \mathrm{C}$. The local current densities obtained were plotted against $\log x$, as shown in Fig. 5, where a clear linear relationship can be seen. Least-square fitting resulted in the following formula:

$$
i(x)=I(52.8-52.0 \log x)
$$

The current distribution determined for the $\mathrm{Al}$ electrodeposition in the $\mathrm{DMSO}_{2}$ bath using Eq. 2 was almost the same as that obtained using the general formula (Eq. 1). The local current densities for the bath containing TETA were also estimated in the same manner, and it can be seen in Fig. 5 that the values are almost on the line representing Eq. 2. While the addition of polyethylene amines has been previously shown to increase the overvoltage for the electrodeposition of $\mathrm{Al}$ [22], the results of the present study demonstrate negligible influence on the current distribution in the Hull cell test. This fact suggests that the resistance of the bulk electrolyte is much higher than that of the electrode reaction in the configuration of the Hull cell, and thus the former dominates the current distribution. Eq. 2 was subsequently used to determine the local current density for all of the additives.

The Hull cell tests were performed for the $\mathrm{DMSO}_{2}-\mathrm{AlCl}_{3}$ baths containing $0-0.4$ 
mol of EDA, DETA, TETA, TEPA, or PEHA, and the results are summarized in Fig. 6. As was already shown in Fig. 2, the Hull cell test confirmed that, in the absence of an additive, no bright $\mathrm{Al}$ deposit was obtained at any current density ( $0 \mathrm{~mol}$ of EDA, Fig. 6a). The tests also showed that EDA had no effect as a brightener, even when the quantity was as high as $0.4 \mathrm{~mol}$ (Fig. 6a). On the addition of a small amount of DETA, a narrow area of bright deposit was obtained on the panel (Fig. 6b). However, further increases in the DETA content resulted in decreases in brightness, with the appearance becoming quite dull above $0.2 \mathrm{~mol}$. The increase in the DETA content also increased the size of the burnt area. Bright $\mathrm{Al}$ deposits were formed over a much wider area on the addition of TETA (Fig. 6c), with contents of only 0.025 or 0.05 mol being sufficient. Similar to the DETA, an increase in TETA content brought about a decrease in brightness and an increase in the size of the burnt area. The same trends were observed in the cases of TEPA and PEHA (Figs. 6d-6e). As the molecular mass of the additive increased from TETA to TEPA and PEHA, the bright area that appeared on the cathode panel shrank in size (Figs. 6c-6e). Among the conditions tested in this study, the addition of TETA at a content of $0.05 \mathrm{~mol}$ gave the best results, with bright Al deposits evident in a wide area of the cathode panel. The bright area on the panel was found to correspond to the current density range of about $25-110 \mathrm{~mA} \mathrm{~cm}^{-2}$. It is preferable that bright deposits can be obtained over a wide range of current densities, because objects to be electroplated often have complex shapes, with the local current densities varying across the structures.

The Hull cell tests also revealed variations in preferential crystal orientation of the $\mathrm{Al}$ deposits depending on the additive and the local current density. Fig. 7 shows the XRD patterns of the deposits at various positions on the cathode panels obtained from 
the baths with no additive and 0.05 mol TETA. In each of the patterns in the absence of additive, diffraction peaks of $\mathrm{Al}$ (111), (200), (220), and (311) were observed, and their relative intensities were almost the same as those of the powder pattern, indicating that the deposit from the bath with no additive was composed of randomly oriented Al crystals, regardless of the local current density. On the other hand, variation in the preferential orientation depending on the position of the cathode panel, i.e., local current density, was observed when TETA was used as an additive. In the patterns of the deposit at position $x=7 \mathrm{~cm}$, the intensity of the $\mathrm{Al}$ (111) reflection was much higher than those of the others. With decreasing $x$, the relative intensity of the Al (111) reflection decreased, while that of $\mathrm{Al}$ (200) increased. At position $x=2 \mathrm{~cm}$, the $\mathrm{Al}$ (200) reflection was notably high in comparison to the $\mathrm{Al}$ (111) reflection, which indicates that the preferential orientation of the $\mathrm{Al}$ deposit varied from $<111>$ to $<100>$ with increasing local current density. This result agrees with Pangarov's theory [27], which predicts that fcc metals electrodeposited at low over voltage have <111> preferential orientation, and that this changes from $\langle 111\rangle$ to $\langle 100\rangle$ with increasing over voltage. The observed difference in the orientation behavior between the deposits obtained with and without TETA may have been caused by changes in the surface energy of the Al crystals through the adsorption of the additive molecules on the Al deposit during the electrodeposition. Although variations in the preferential orientation were observed, no correlation was found between the preferential orientation and the brightness of the Al deposit. The reflectance of the deposit from the bath with TETA was almost constant at the high level of $70 \%$ in between $x=2$ and $6 \mathrm{~cm}$ (Fig. 3), while the preferential orientation varied from $<100>$ to $<111>$ in this range (Fig. 7).

The results suggest that the brightness of the Al deposits were exclusively 
influenced by the surface morphology. Typical SEM images of the burnt, dull-white, and bright $\mathrm{Al}$ deposits on the cathode panels are shown in Fig 8. In the burnt area, the deposit appears to have relatively large nodules, providing high surface roughness (Fig. 8a). The dull-white deposit can be seen to be composed of faceted crystal grains of 0.5-3 $\mu \mathrm{m}$ in size (Fig. 8b), producing a relatively rough Al surface. In contrast, a smooth surface composed of much smaller grains on the order of $20-50 \mathrm{~nm}$ can be observed for the bright deposits (Figs. 8c and 8d). These images demonstrate that the microstructural differences were the origin of the variations in the reflectance and the visual appearance of the deposits. The deposits with a smoother surface exhibited a bright metallic luster, while those with a rougher surface appeared less bright, which was because the microscopically rough surface diffused the incident light in many different directions. Figs. $8 \mathrm{c}$ and d show the surfaces of the deposits at positions $x=2$ and $6 \mathrm{~cm}$ from the bath containing $0.05 \mathrm{~mol}$ TETA. Although these deposits were found to have different preferential orientations, as described above, they had flat surfaces, irrespective of the crystal orientation, as the crystal grains were quite small.

The smooth, bright $\mathrm{Al}$ deposits composed of the refined crystal grains seem to be formed by the same mechanism as for conventional aqueous electroplating using typical brighteners. The additive molecules are preferentially adsorbed onto protruding parts of the deposit during the electrodeposition process, and thereby suppress the crystal growth at that point. The electrodeposition proceeds at the more concave parts of the surface, thereby reducing the presence of surface irregularities [23, 28]. The polyethylene amines would adsorb onto the Al crystals through their nitrogen atoms, which have a lone pair of electrons; hence, the ability to adsorb should increase with molecular mass $\left(m_{\mathrm{a}}\right)$, or the number of nitrogen atoms of the amine. This hypothesis 
suggests that an amine with a small $m_{\mathrm{a}}$ should produce the same effects as a larger amine if it was added to the bath at a higher concentration. However, the results obtained in this study have demonstrated that this is not the case. The brightness of the Al deposit obtained by the addition of TETA was not reproduced by the other polyethylene amines, regardless of concentration. This indicates that the size and/or structure of the additive is important for it to function effectively as a brightener for the electrodeposition of Al.

\section{Conclusions}

Hull cell tests were carried out to examine a series of polyethylene amines for use as brighteners in the electrodeposition of $\mathrm{Al}$ from a $\mathrm{DMSO}_{2}-\mathrm{AlCl}_{3}$ bath. The tests identified the current density ranges where bright, semi-bright, dull, burnt, and streaked deposits were obtained with each additive. It was confirmed that bright Al deposits could not be obtained in the absence of an additive at any current density; however, on addition of DETA, TETA, TEPA, or PEHA, a bright area of deposit was formed on the cathode panel. When 0.05 mol of TETA was added, the bright deposit exhibited specular reflectances of above $60 \%$ over the widest range of current densities. It was therefore concluded that TETA was the most effective brightener out of the amines tested in this study. XRD analysis demonstrated no correlation between brightness and preferential crystal orientation, which along with the acquired SEM images, indicated that the brightness was exclusively influenced by the surface morphology of the Al deposit.

\section{Acknowledgment}

This work was supported by a MEXT/JSPS Grant-in-Aid for Scientific Research 
(B) (Grant No. 24360308). 


\section{References}

[1] M. Jafarian, M.G. Mahjani, F. Gobal, I. Danaee, J Appl Electrochem, 36 (2006) 1169-1173.

[2] M. Jafarian, F. Gobal, I. Danaee, M.G. Mahjani, Electrochim Acta, 52 (2007) 5437-5443.

[3] Y.G. Zhao, T.J. VanderNoot, Electrochim Acta, 42 (1997) 3-13.

[4] S.Z. El Abedin, E.M. Moustafa, R. Hempelmann, H. Natter, F. Endres, Electrochem Commun, 7 (2005) 1111-1116.

[5] J.K. Chang, S.Y. Chen, W.T. Tsai, M.J. Deng, I.W. Sun, Electrochem Commun, 9 (2007) 1602-1606.

[6] F. Endres, A.P. Abbott, D.R. MacFarlane, Electrodeposition from ionic liquids, Wiley-VCH, 2008.

[7] L. Barchi, U. Bardi, S. Caporali, M. Fantini, A. Scrivani, A. Scrivani, Prog Org Coat, 67 (2010) 146-151.

[8] A. Abbott, F. Qiu, H. Abood, M. Ali, K. Ryder, Physical Chemistry Chemical Physics, 12 (2010) 1862-1872.

[9] S. Takahashi, K. Akimoto, I. Saeki, Journal of the Surface Finishing Society of Japan, 40 (1989) 134-135.

[10] A.P. Abbott, C.A. Eardley, N.R.S. Farley, G.A. Griffith, A. Pratt, J Appl Electrochem, 31 (2001) 1345-1350.

[11] Q. Liao, W.R. Pitner, G. Stewart, C.L. Hussey, G.R. Stafford, J Electrochem Soc, 144 (1997) 936-943.

[12] F.H. Hurley, T.P. Wier, J Electrochem Soc, 98 (1951) 207-212.

[13] L. Legrand, A. Tranchant, R. Messina, F. Romain, A. Lautie, Inorganic Chemistry, 35 (1996) 1310-1312.

[14] L. Legrand, A. Tranchant, R. Messina, J Electrochem Soc, 141 (1994) 378-382.

[15] T. Hirato, J. Fransaer, J.P. Celis, J Electrochem Soc, 148 (2001) C280-C283.

[16] M. Miyake, S. Tajikara, T. Hirato, Surf Coat Tech, 205 (2011) 5141-5146.

[17] M. Miyake, S. Tajikara, T. Hirato, High Temperature Materials and Processes, 30 (2011) 485-489.

[18] S. Shiomi, M. Miyake, T. Hirato, A. Sato, Mater Trans, 52 (2011) 1216-1221.

[19] S. Shiomi, M. Miyake, T. Hirato, J Electrochem Soc, 159 (2012) D225-D229.

[20] T. Jiang, M.J.C. Brym, G. Dube, A. Lasia, G.M. Brisard, Surface \& Coatings Technology, 201 (2007) 6309-6317.

[21] H. Hoshi, A. Okamoto, S. Andoh, Hitachi Metals Technical Review, 27 (2011) 20-27.

[22] M. Miyake, Y. Kubo, T. Hirato, Journal of The Surface Finishing Society of Japan, 64 (2013) 364-367. 
[23] L. ONICIU, L. MURESAN, Journal of Applied Electrochemistry, 21 (1991) 565-574.

[24] J.W. Dini, Electrodeposition: the materials science of coatings and substrates, Noyes Publications, New York, USA, 1993.

[25] J.H. Lindsay, Plating and Surface Finishing, 87 (2000) 10-13.

[26] M. Matlosz, C. Creton, C. Clerc, D. Landolt, J Electrochem Soc, 134 (1987) 3015-3021.

[27] N.A. Pangarov, Journal of Electroanalytical Chemistry, 9 (1965) 70-85.

[28] T.C. Franklin, Surf Coat Tech, 30 (1987) 415-428. 


\section{Figure captions}

Fig. 1: Schematic view of Hull cell.

Fig. 2: Appearances of $\mathrm{Al}$ deposits on Hull cell cathode panels obtained from $\mathrm{DMSO}_{2}-\mathrm{AlCl}_{3}$ baths containing (a) no additives, (b) 0.05 mol TETA, and (c) 0.05 mol PEHA. The panels are located on a grid with a $1 \mathrm{~cm}$ pitch to enable clear observation of reflections.

Fig. 3: Normal incidence reflectance of $\mathrm{Al}$ deposits on Hull cell cathode panels obtained from $\mathrm{DMSO}_{2}-\mathrm{AlCl}_{3}$ baths containing (a) no additives, (b) $0.05 \mathrm{~mol}$ TETA, and (c) 0.05 mol PEHA.

Fig. 4: Cross-sectional SEM images of $\mathrm{Al}$ deposit on a $\mathrm{Cu}$ cathode panel at a distance of (a) 3, (b) 4, (c) 5, and (d) $7 \mathrm{~cm}$ from the high current end of the cathode panel.

Fig. 5: Current density distribution along the cathode panel, derived from the measured thickness of the $\mathrm{Al}$ deposits. Solid squares and open circles indicate the data for the baths containing no additive and 0.05 mol TETA, respectively.

Fig. 6: Hull cell patterns of the $\mathrm{Al}$ deposits for $\mathrm{DMSO}_{2}-\mathrm{AlCl}_{3}$ baths containing $0-0.4$ mol of (a) EDA, (b) DETA, (c) TETA, (d) TEPA, or (e) PEHA.

Fig. 7: XRD patterns of $\mathrm{Al}$ deposits from $\mathrm{DMSO}_{2}-\mathrm{AlCl}_{3}$ baths containing no additives or 0.05 mol TETA on $\mathrm{Cu}$ cathode panels at different positions. The peaks 
indicated by solid circles are diffractions from the $\mathrm{Cu}$ substrate.

Fig. 8: Surface SEM images of (a) burnt, (b) dull-white, and (c,d) bright Al deposits obtained from $\mathrm{DMSO}_{2}-\mathrm{AlCl}_{3}$ baths containing (a,b) no additive and (c,d) 0.05 mol TETA on cathode panels at positions $x=$ (a) $1 \mathrm{~cm},(\mathrm{~b}, \mathrm{c}) 2 \mathrm{~cm}$, and (d) 6 $\mathrm{cm}$. 


\section{Cathode}

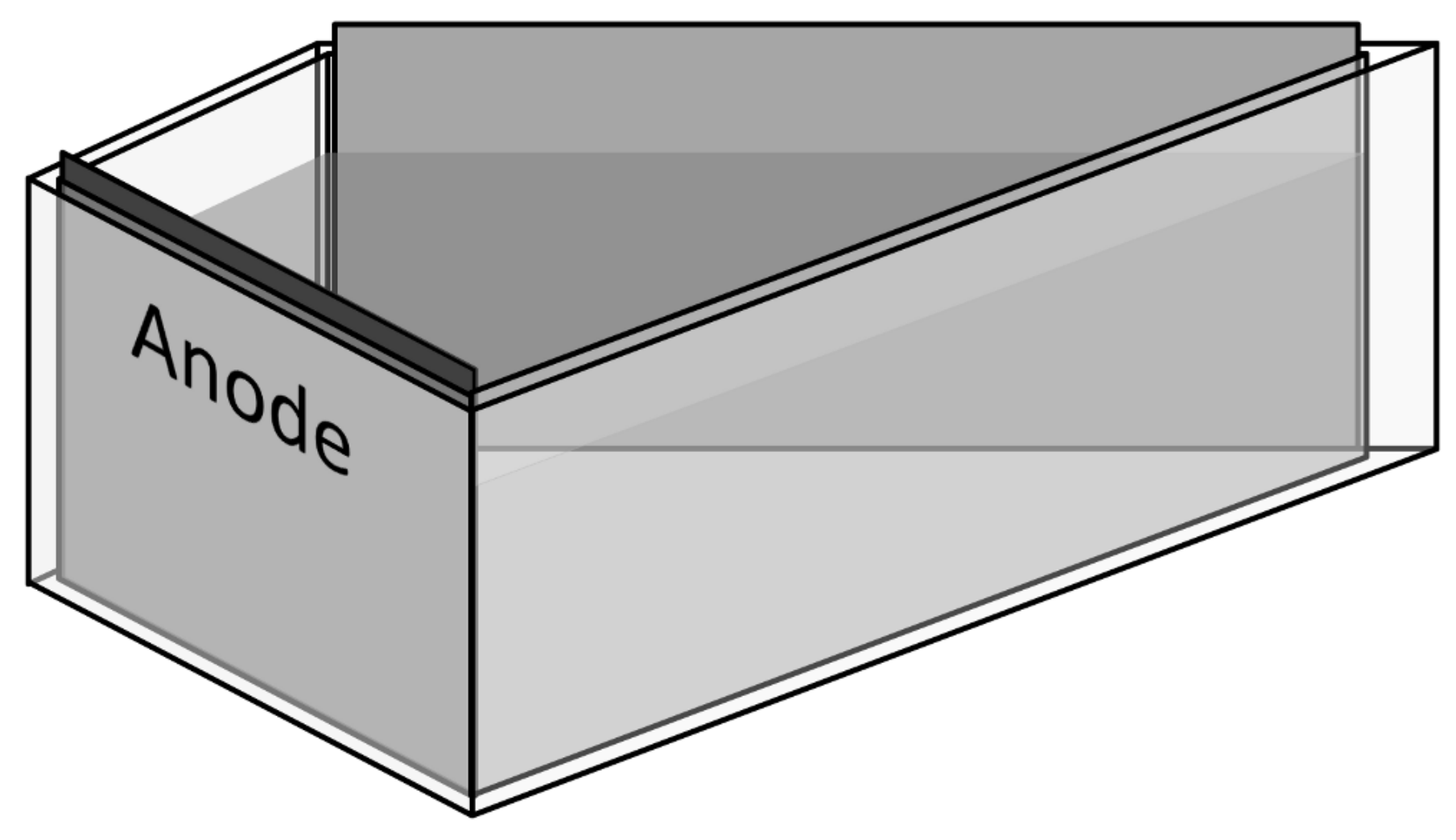

Fig. 1 


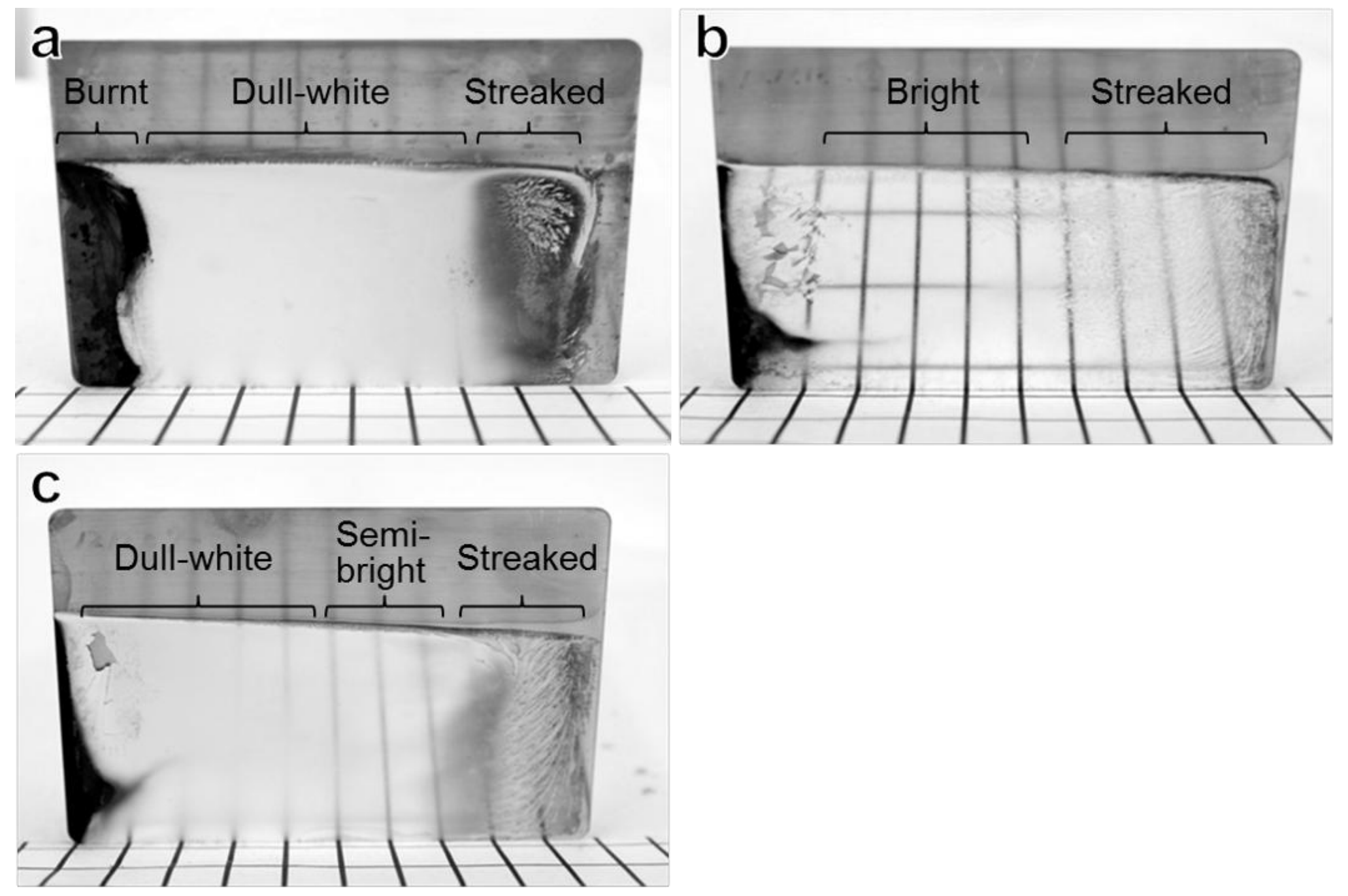

Fig. 2 


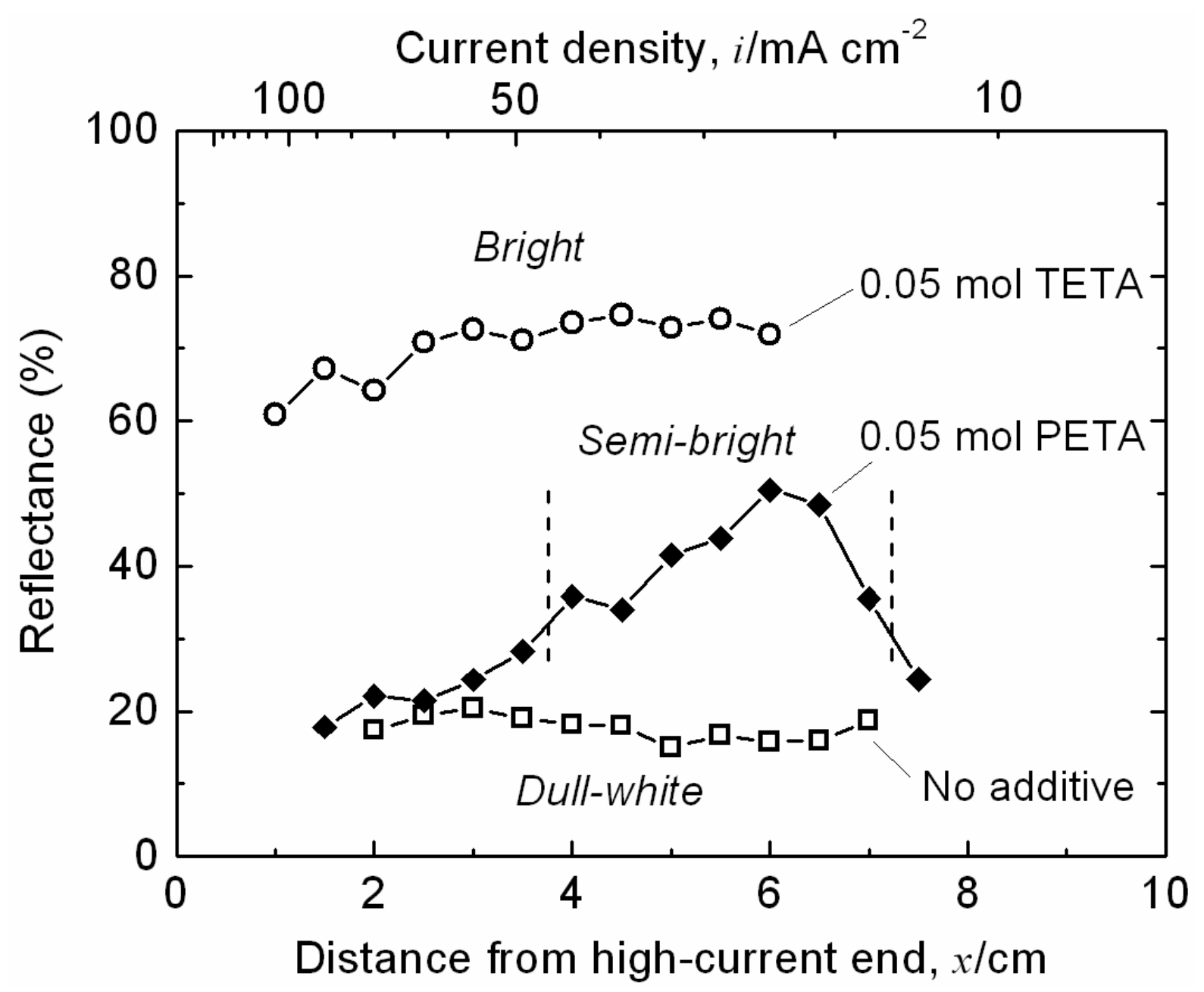

Fig. 3 


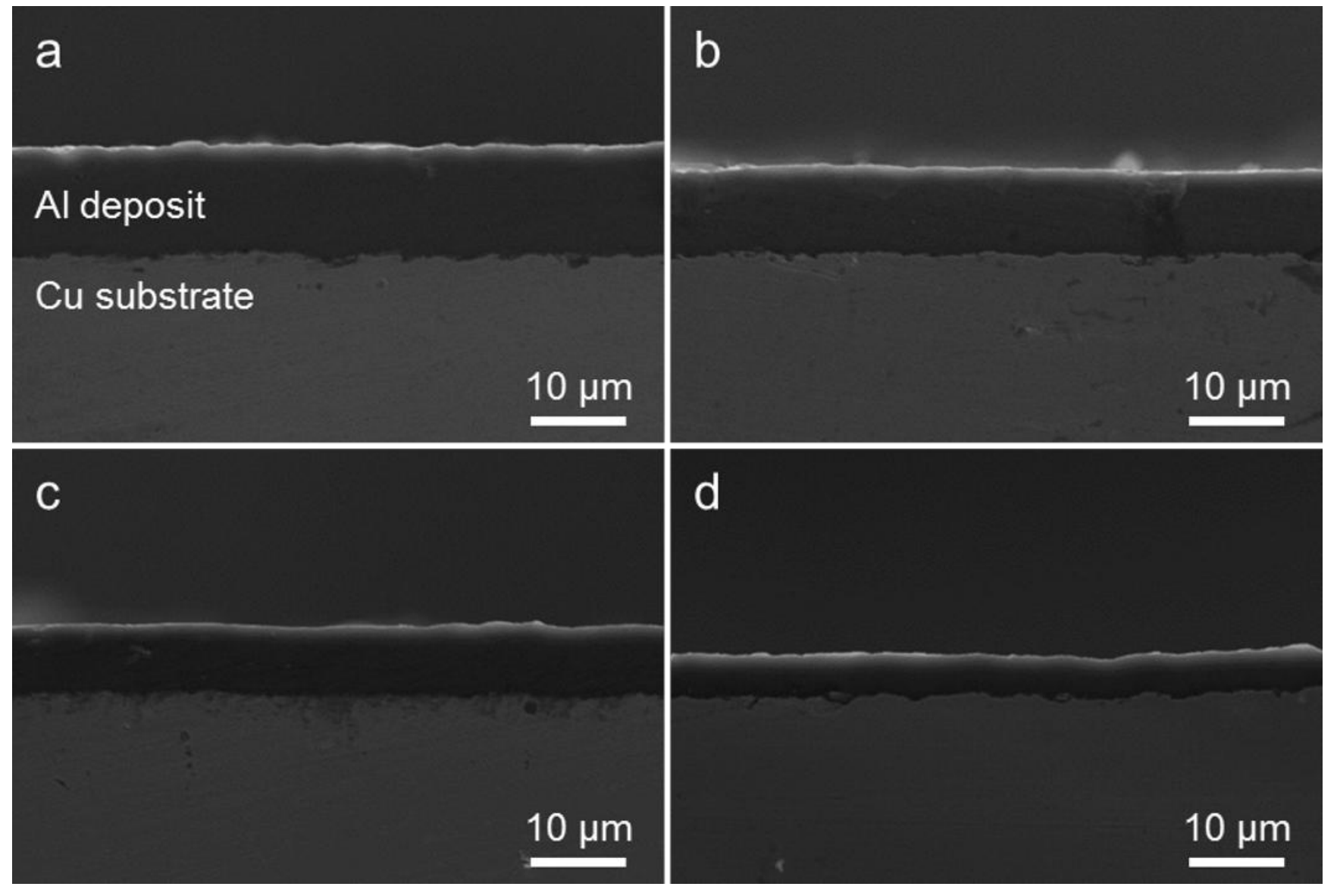

Fig. 4 


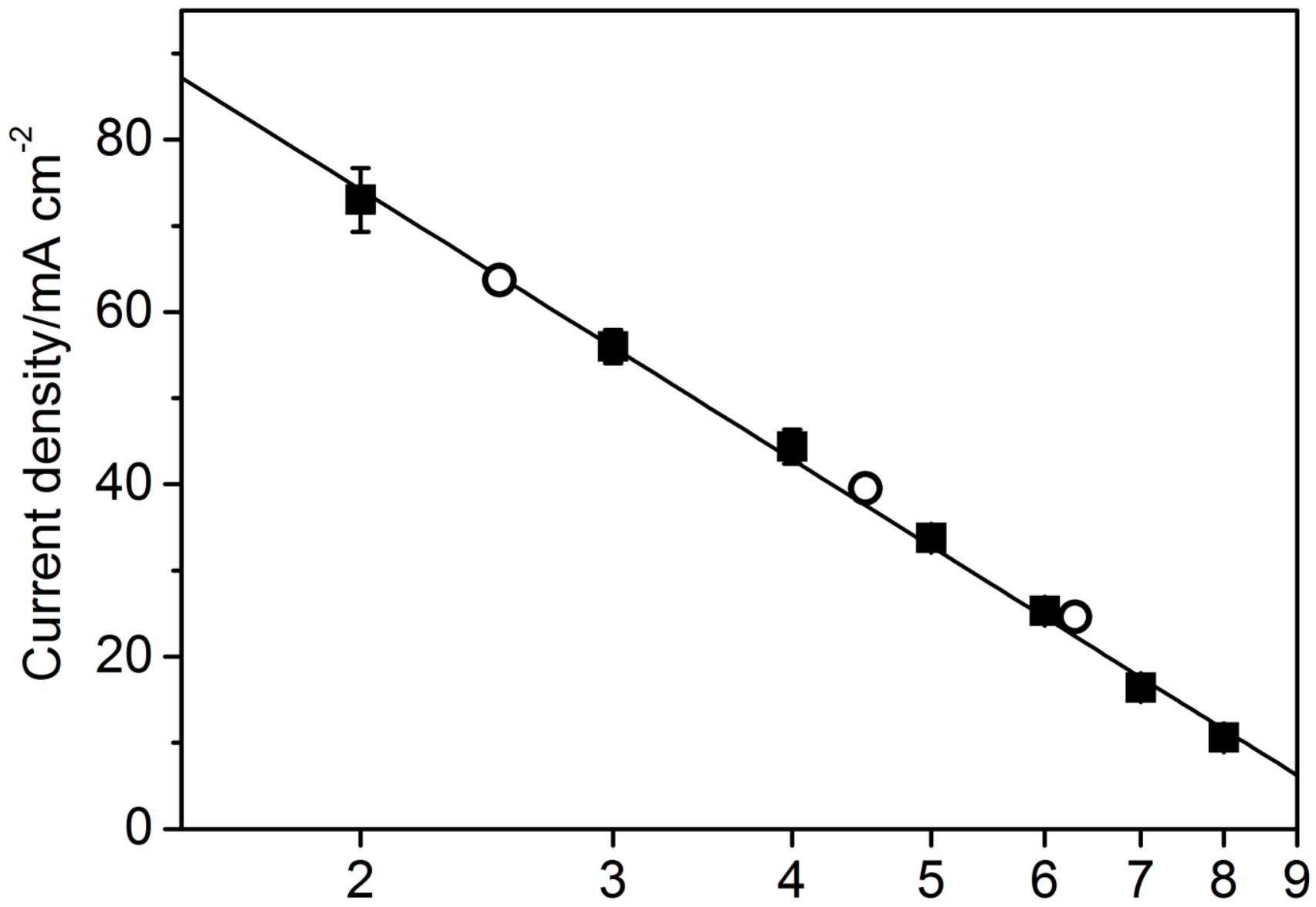

Distance from high-current end, $x / \mathrm{cm}$

Fig. 5 

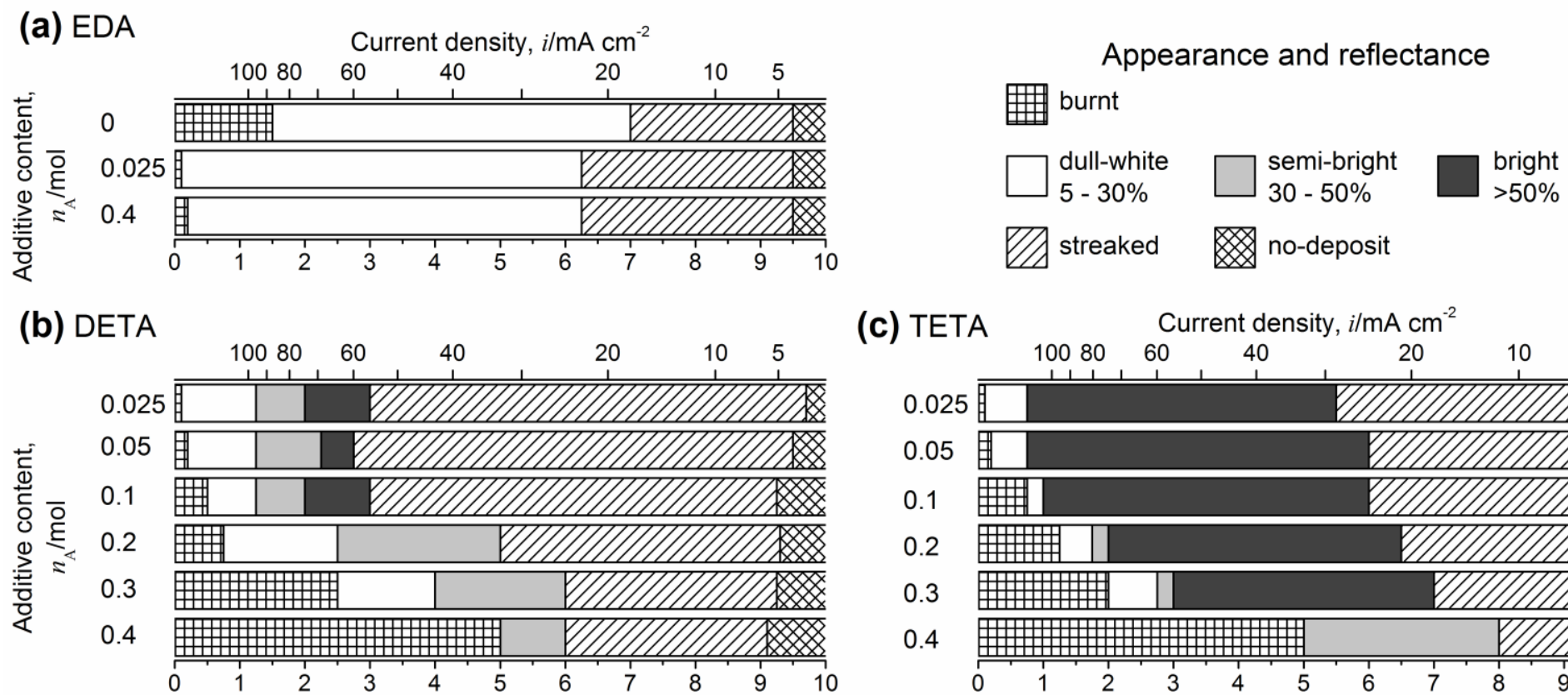

(c) TETA Current density, $i / \mathrm{mA} \mathrm{cm}^{-2}$
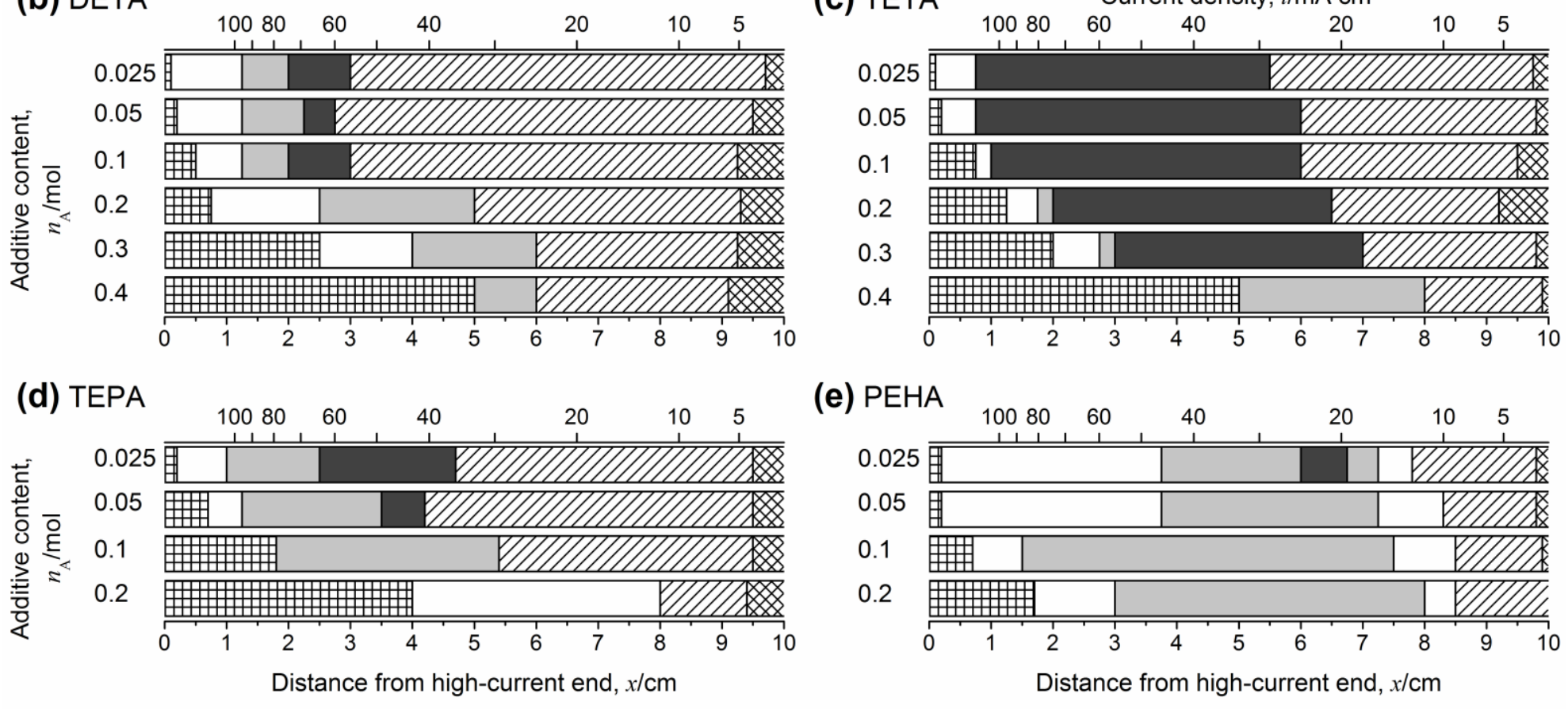

Fig. 6 

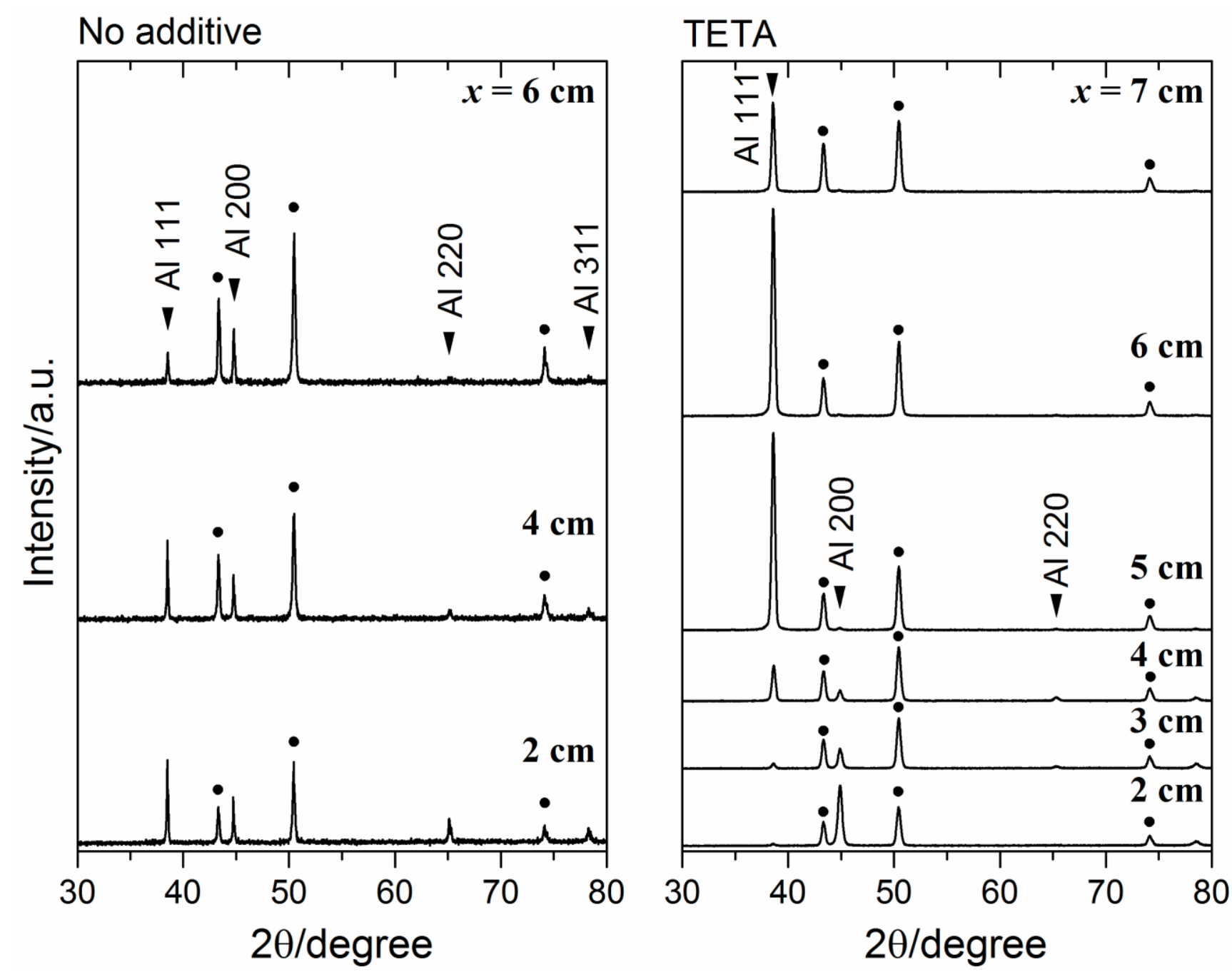

Fig. 7 


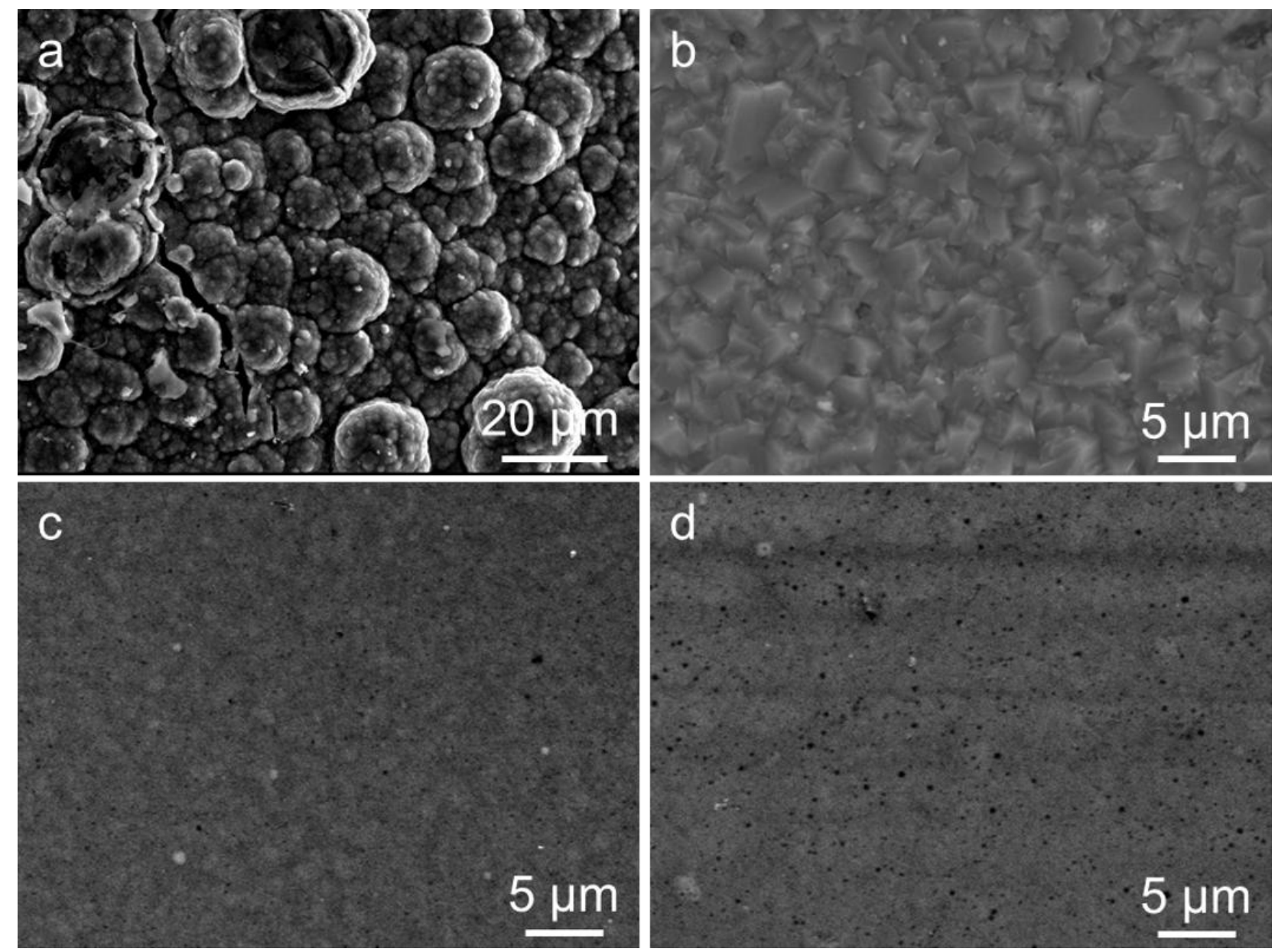

Fig. 8 